\title{
The earliest record of a diogenid hermit crab from the Late Jurassic of the southern Polish Uplands, with notes on paguroid carapace terminology
}

René H.B. Fraaije, Wiesław Krzemiński, Barry W.M. Van Bakel, Ewa Krzemińska, and John W.M. Jagt Acta Palaeontologica Polonica 57 (3), 2012: 655-660 doi: http://dx.doi.org/10.4202/app.2011.0052

A new species of diogenid paguroid, Eopaguropsis nidiaquilae, the earliest known member of the family to date, is recorded from sponge-reefal strata of Oxfordian (Late Jurassic) age in the southern Polish Uplands. Morphological features of the carapace suggest that the family Diogenidae diverged from other paguroid lineages such as the Pylochelidae and Parapaguridae, long before the Oxfordian Stage (161.2-155.7 Ma). The typically deep, V-shaped cervical groove of diogenids most likely was the product of fusion of the branchiocardiac and cervical grooves of their predecessors.

Key words: Paguroidea, Diogenidae, carapace morphology, evolution, Late Jurassic, Oxfordian, Poland.

René H.B. Fraaije [info@ oertijdmuseum.nl], Oertijdmuseum De

Groene Poort, Bosscheweg 80, NL-5283WB Boxtel, the

Netherlands; Wiesław Krzemiński [krzeminski@muzeum.pan.krakow.pl

], Ewa Krzemińska [krzeminska@isez.pan.krakow.pl], Institute of Systematics and Evolution of Animals, Polish Academy of Sciences, ul.

Sławkowska 17, PL-31-016 Kraków, Poland; Barry W.M. Van Bakel [barryvanbakel@ gmail.com ], Oertijdmuseum De Groene Poort, Bosscheweg 80, NL-5283 WB Boxtel, the Netherlands; and, Nederlands Centrum voor Biodiversiteit (Naturalis), P.O. Box 9517, NL-2300 RA Leiden, the Netherlands; John W.M. Jagt [john.jagt@ maastricht.nl], Natuurhistorisch Museum Maastricht, de Bosquetplein 6-7, NL-6211 KJ Maastricht, the Netherlands.

This is an open-access article distributed under the terms of the Creative Commons Attribution License (for details please see creativecommons.org), which permits unrestricted use, distribution, and reproduction in any medium, provided the original author and source are credited. 
Forif Full text $(330.3 \mathrm{kB})$ 